\title{
Using the full potential: regional planning based on local potentials and exergy
}

\author{
A. van den Dobbelsteen ${ }^{1}$, R. Roggema ${ }^{2}$, K. Stegenga ${ }^{3}$ \\ \& S. Slabbers ${ }^{4}$ \\ ${ }^{I}$ Delft University of Technology, The Netherlands \\ ${ }^{2}$ Province of Groningen / Groningen University, The Netherlands \\ ${ }^{3}$ Stegenga, Workshop for Urban Planning, Tilburg, The Netherlands \\ ${ }^{4}$ Bosch Slabbers Landscape Architects, The Hague, The Netherlands
}

\begin{abstract}
Climate change and the depletion of fossil energy resources pose a serious threat to many parts of the world. The northern region of the Netherlands, partly below sea level and currently depending importantly on the exploitation of natural gas, is a clear example of this. This paper discusses the studies undertaken to propose a radical change to the region, leading to a different approach to spatial planning, based on local potentials and the exergy principle. So far, energy has hardly been an influence in regional and urban planning. Nevertheless, smart deployment of local potentials for energy provision, based on the vernacular characteristics, will mean a new paradigm for spatial planning. Thorough analysis of the local climatic, landscape, geophysical, cultural, and technical characteristics with a focus on energy potential leads to better insight into the most effective energy provision opportunities in the areas of a region. In addition, the concept of low-exergy design - based on using high-quality energy for high-grade processes, and re-using the residual waste energy from these in lower-grade processes - will lead to serving more processes and functions by the same amount of primary energy, implying significant benefits for sustainability. Converting the deployment of local potentials and low-exergy design to regional planning, the spatial arrangement of functions will differ from the conventional approach. The new approach will be exemplified by the Grounds for Change project and its mapping results for the Northern Netherlands.
\end{abstract}

Keywords: climate change, local potentials, energy, exergy, spatial planning. 


\section{Introduction}

\subsection{Climate change}

Climate change is a hot issue, literally. The most probable scenario for the global climate is based on the widely supported findings and expectations by the International Panel on Climate Change [1]. In this scenario, within this century, the earth heats up a few degrees. Eternal snow, glaciers and icecaps will melt. Just as by the expansion of the warmer sea water, the sea levels will rise due to this increased run-off of water on the land. This will lead to more and heavier storms. There will be more clouding. A greater difference between wet and arid areas will evolve.

There has been wide discussion about to which extent human actions are to be blamed for climate change. Evidence is stacking up, but whether or not caused by mankind, the developments described are already taking place, and a quick response is necessary.

\subsection{Energy depletion}

While dramatic changes to our climate are taking place, one of its probable causes, consumption of fossil fuel, will become uncertain in the near future. Natural oil and gas reserves are depleting or at least their extraction is becoming more and more complex and expensive. The tendency to again use coal for the generation of electricity will have an even more devastating impact on greenhouse emissions, if not to mention pollutions that seemed to have been almost banished. Many countries now seek refuge to nuclear power but as long as safety issues and the processing of nuclear waste have not been tackled properly, questions may be raised about this. Moreover, sustainable energy is abundant: based on the potential for energy from the sun, wind and water, Jong et al. [2] calculated that the Netherlands alone could already provide the global economy with sufficient energy. However, at this instant local potentials are still insufficiently seized.

\subsection{The Northern Netherlands}

The problems discussed above in particular relate to the Northern region of the Netherlands. The three provinces of Frisia, Groningen and Drenthe are partly below sea level and rely significantly on the exploitation of natural gas, of which the reserves are expected to deplete within 25 years. In spite of the merits of gas trade, the region is economically relatively weak. This problem and the threats of climate change and energy depletion make the Northern Netherlands an interesting test case for drastic measures needed for a sustainable future.

\section{Climate change and the Northern Netherlands}

\subsection{Dramatic developments}

As in most places elsewhere, the most probable scenario of climate change for the Northern Netherlands implies a temperature rise by a few degrees. It will also 
become wetter. The most important impact to region is the rise of the sea, most probably around $60 \mathrm{~cm}$ within this century. This means that in cases of storm and spring tide the level might be three to four times higher, implying a greater risk of flooding. This sea level rise adds to the increased run-off of water from the mainland, building up the pressure from fresh and salt water onto lower areas, especially those below sea level. For a specific ecologically unique area, the Wadden Sea, the sandbanks may never run dry again, diminishing the habitat of seals and foraging birds.
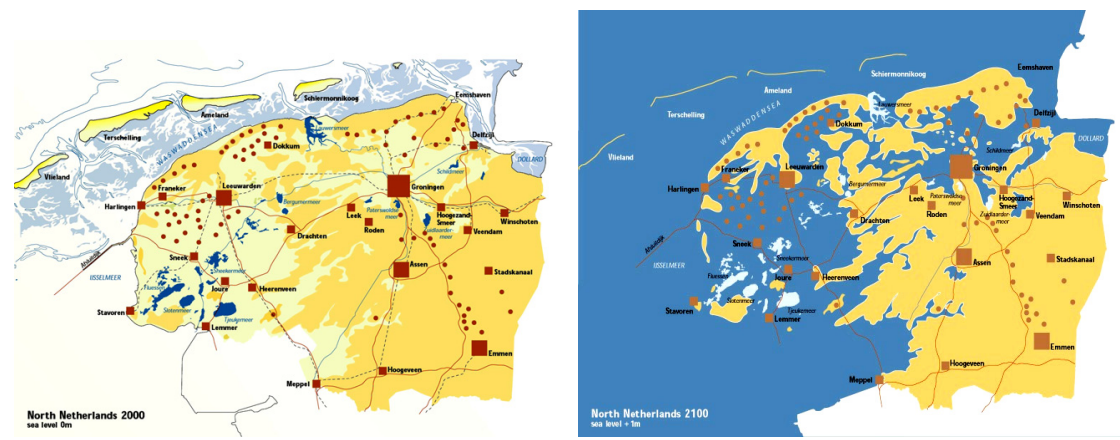

Figure 1: The Northern Netherlands at present (left) and around 2001, sea level risen by 1 meter, after a dike breakthrough (right).

As other climate scenarios are imaginable - for instance, an ocean current inversion leading to local cooling down instead of warming up - the safest policy seems to design a robust plan that can withstand different scenarios.

\subsection{Possibilities to respond}

The increased threat from the sea should be averted, or one should react to it actively. This can be established by making the sea dikes even higher, but the salty seepage will not be reduced by this, and the draining of polders will only aggravate this seepage, apart from the increased demand for energy for draining pumps. Another and perhaps effective strategy will be a layered defence partly interacting with the natural developments: additional defensive banks at sea and flooding areas behind the present dikes, using the deepest polders permanently for water retention. Furthermore, the Northern Netherlands can profit from climate change by touristic-recreative developments. Due to the rise of temperature, comparison with a more southern climate is realistic. Therefore, in the future less energy will be required for heating and hot water (heat), and more for cooling (electricity).

\subsection{Grounds for Change}

The Grounds for Change project was initiated to explore the possibilities of establishing a desirable yet imaginable future image of the Northern Netherlands. 
It led to a new sustainable approach to regional planning and specific measures related to, for instance, water management, energy provision and habitats for living, working and leisure. The approach can be applied to any other region in the world. Based on the boundary conditions chosen, different images may evolve, which is demonstrated by the two reports published after Grounds for Change, Roggema et al. [3] and Noorman et al. [4]. There is not one single vision on future developments... This paper reflects the ideas of the regional design team of Grounds for Change.

\section{A different approach}

\subsection{Another attitude}

Rather than fearing the doom of climate change and energy depletion, they can be used also as a catalyst for sustainable redevelopment. Huge efforts can be put into the mitigation the effects expected, and this is very necessary indeed. However, one can also accept the most probable forecasts and use these in spatial planning. For the Northern Netherlands, prolonging 'business as usual' (enforcing the existing coastal defences and draining all polders) would cause too many problems to cope with; therefore, a new paradigm was found in cooperating with the sea rather than fighting it, and basing spatial planning on local energy potentials and in accordance with the exergy principle rather than extrapolating current developments.

\subsection{Forecasting, backcasting and backtracking}

First, in order to set the path for future sustainable developments, there are different time-based approaches.

- Forecasting is needed when we want to estimate the consequences of current developments and our own intervention on long-term effects, such as the issues of climate change and depletion of resources.

- Backcasting involves the description of a desired future state (sustainable and based on the needs that need to be met), translating this state back to strategies and measures we need to develop now.

- By means of backtracking, solutions are based on historical circumstances at the time when there still was a sustainable equilibrium. This sustainable past may be an instance for planning directions, for which perhaps certain valuable historical, natural or cultural features or circumstances can be brought back to new design.

Figure 2 clarifies the three approaches.

Forecasting is useful to predict trends that have developed over some time already, but is not very effective to establish a great leap toward a sustainable future. A better, more effective method for substantial change is backcasting, but one could consider this method rather detached from real life and how it evolved throughout the centuries. Therefore, backtracking can be used to link the present 
to qualities of the past. None of the methods should be applied alone. We found that the simultaneous use of all three of them means synergy, picking the best solutions from history, the present, and the imagined and desirable future.

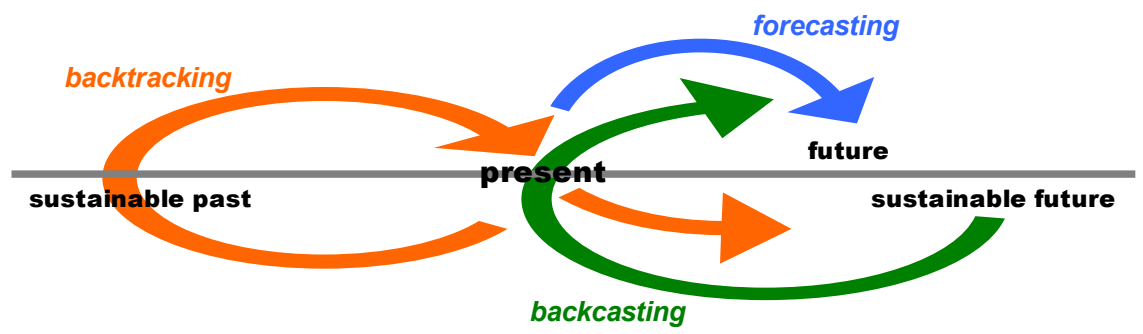

Figure 2: Graphical explanation of the forecasting, backcasting and backtracking methods.

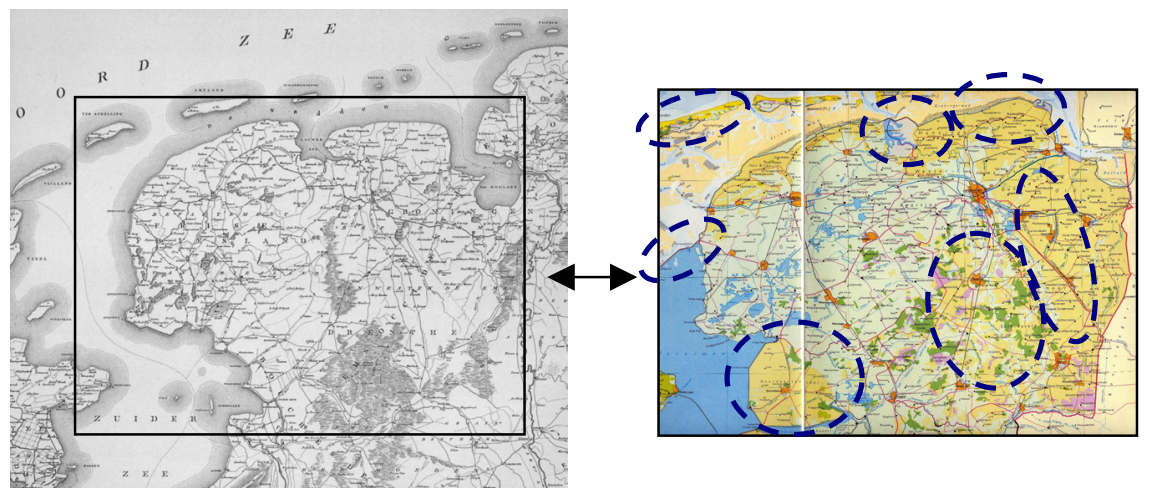

Figure 3: Map of the Northern Netherlands in 1810 and at present with some major changes.

\subsection{Major changes to be expected}

Around 1810, the landscape of the Northern Netherlands had hardly altered since centuries (Figure 3, left). After 1810, some major changes altered the regional landscape: containment of sea inlets and protective measures against the sea, polder extensions into the Wadden Sea, exploitation of the higher peat areas (the Peat Colonies), irrigation of the higher plateau through the introduction of artificial fertilisers, taking a whole new area from the sea (the North-East Polder), and the closure of the Southern Sea (IJssel Lake) that made this possible (Figure 3, right). Less visible is the exploitation of natural oil and gas.

\section{Local potentials}

Local strengths are usually neglected in regional and urban planning, especially with regard to local self-provision of energy. A different approach is supported 
by energy potential maps. Analysis of the climatic conditions of the region, its geographical features and technical-cultural usage are among the issues to be studied to draw these maps. Some examples will be given here.

\subsection{Energy potential maps for the Northern Netherlands}

The wind potential map of Figure 4 shows the average wind force in the region (in Beaufort), indicating high potentials near the coast line. The sunshine potential map of Figure 4 gives mean sunshine hours, pointing out the areas most suitable for active or passive generation of solar energy.
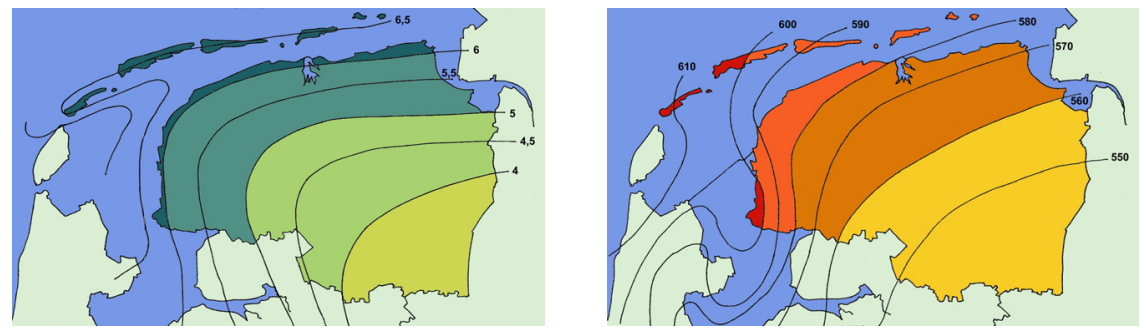

Figure 4: Average wind force (left) and average sunshine hours (right).
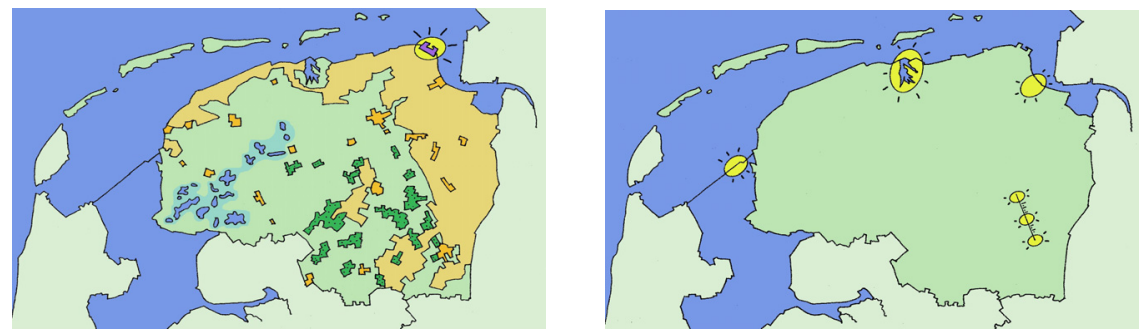

Figure 5: Location of biomass production (left) and water potentials (right).

Figure 5 gives the potential map for biomass, an interesting patchwork of agriculture, forests, lakeshore plants and domestic waste (produced in living areas), which can be made useful as local energy resource. Figure 5 depicts a few of the many opportunities for using water in the energy cycle: a drain plant at the IJssel Lake closure dike, a tidal plant in the former Lauwers sea inlet, osmosis plants at the borders of salt and fresh water, and plants and heat pumps making use of the great difference in height (seepage) at the edge of the Drenthe plateau.

Not presented here is the underground potential for gas and oil, hot geothermal water or storage of $\mathrm{CO}_{2}$. An interesting opportunity is related to former gas drill holes, by means of which geothermal heat can be extracted, and around which therefore new areas for living may evolve in order to reduce heat transportation. 


\subsection{The energy mix map}

When all potential maps are combined, an energy mix map evolves (Figure 6), indicating the energy resources most logical when optimally deploying the local potentials. This map can also be used for choosing new areas of development, to be situated at the places where energy is abundant.

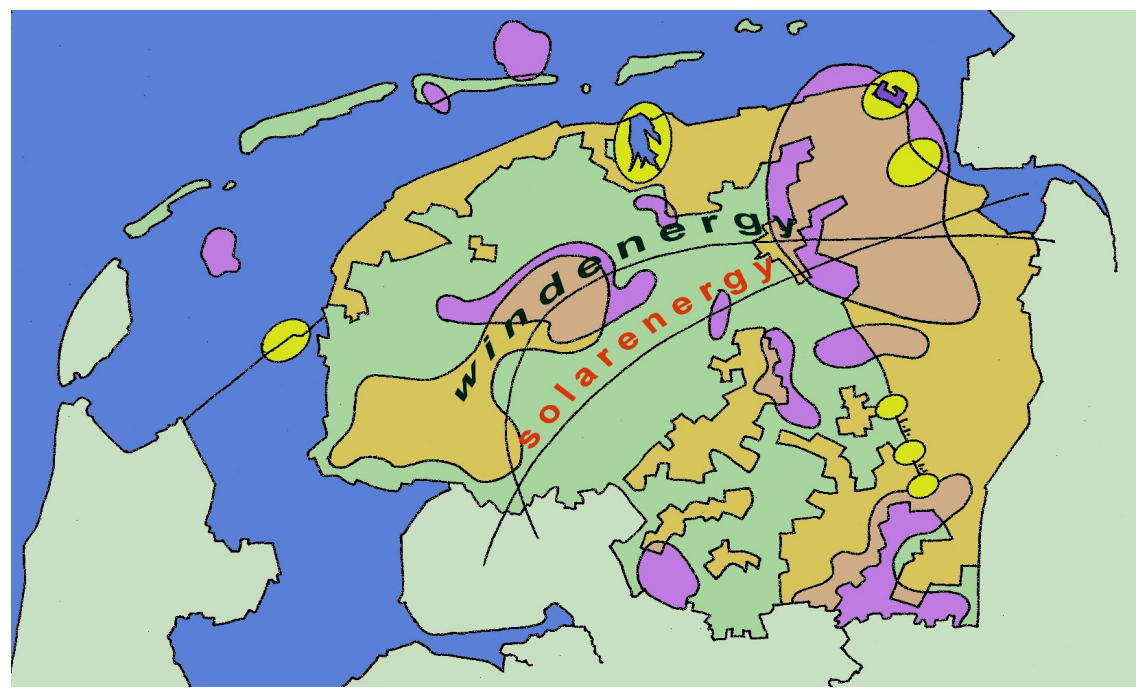

Figure 6: The energy mix map, evolving from the overlapping of all energy potential maps.

\section{Exergy}

\subsection{What is exergy?}

An extra dimension can be added to the method of energy potential maps by introducing the concept of exergy. As opposed to entropy, which can be considered the non-useful waste energy, exergy is the useful part in energy, the part that can be used to perform work, a measure of energy quality. In accordance with the Second Law of Thermodynamics processes constantly develop towards a state of increasing entropy (and decreasing exergy). The quintessence of this is that energy of a high-quality level (great exergy) should be used for high-grade functions before it transforms into a lower-quality state.

\subsection{Low-exergy approach}

Nowadays, households of the colder and temperate Northern hemisphere use high-caloric heat from the combusting of gas, gasoline or coal (at least $1200^{\circ} \mathrm{C}$ ), to heat up their houses to the pleasant level of $20-22^{\circ} \mathrm{C}$. This process would be much more effective if steps were inserted in-between, as in a cascade: the high 
temperature would be used only in heavy industrial processes, of which waste heat could be used in lower-grade functions such as manufacturing processes, horticulture, and consequently for residential heating (Figure 7).

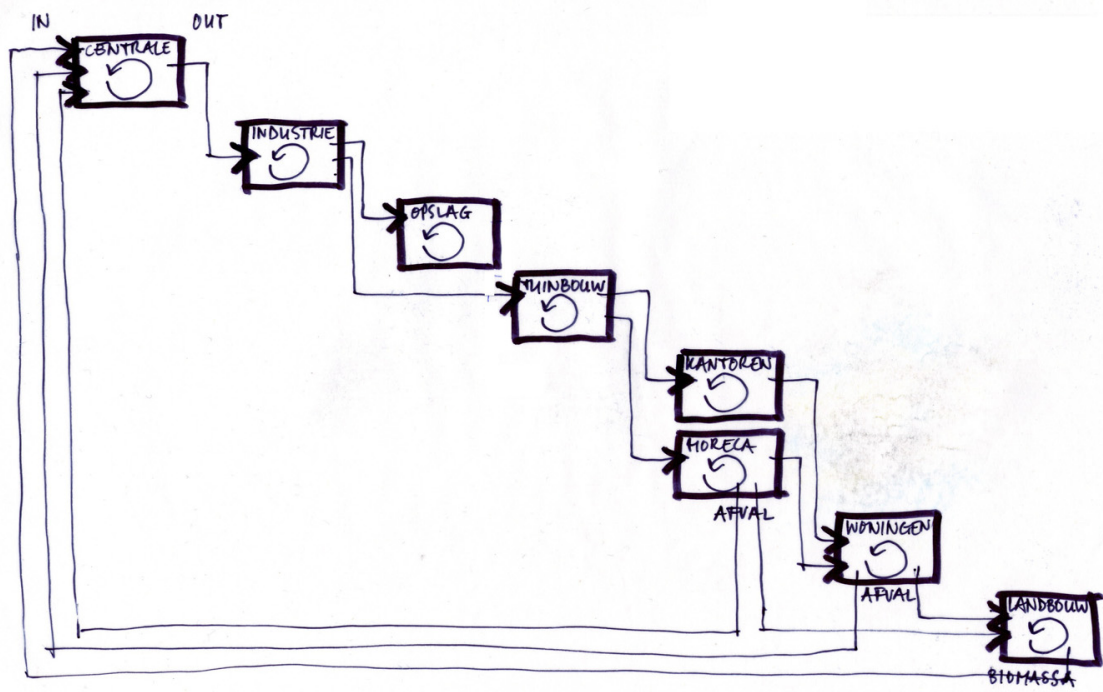

Figure 7: Graphical example of a heat cascade.

Thus, four instead of just one function would be served by the same amount of primary energy, a very significant contribution to a sustainable energy system.

\subsection{The meaning for spatial planning}

The exergy principle can be introduced to many scales of spatial design: region, city, district and building. It implies the concentration or mixing of functions (industry, agriculture, horticulture, commercial buildings, housing, etcetera), each embodying one of the steps in the cascade. Low-caloric heat should not be transported over long distances: heat losses would be too big. This would mean a radical shift from the separation of functions by present-day planning: horticulture near industry, residences near horticulture, or even integrated with it.

For the Northern Netherlands this means that the high-graded industry and power plant near Eemshaven and Delfzijl (province of Groningen) could be a starting-point for heat cascades, but this would also be possible on a smaller scale, starting from small industries in cities, districts or villages.

\section{New images}

\subsection{The regional plan}

Based on the energy potential maps and the exergy principle discussed in this paper, the current topography and not least a landscape analysis (Figure 8, left), a 
new map (Figure 8) could be drawn for the Northern Netherlands. This map depicts a possible future in which some connections to the sea are opened again and utilised for energy generation, in which a larger part of Frisia and the lower parts of Groningen have become lakes again, and in which the entire spatial planning is based on an effective use of local energy potentials (sun, wind, water, biomass, geothermal heat, etcetera) and exergy (heat cascading).

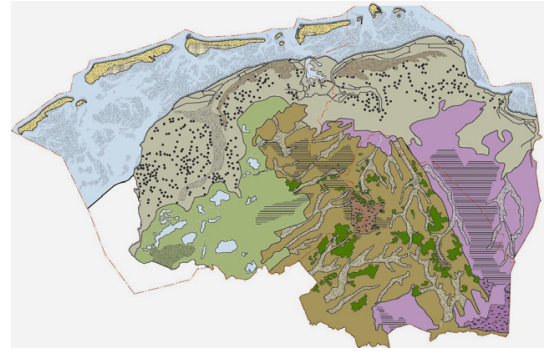

Figure 8: Landscape analysis (left) and a new map of the Northern Netherlands (right).

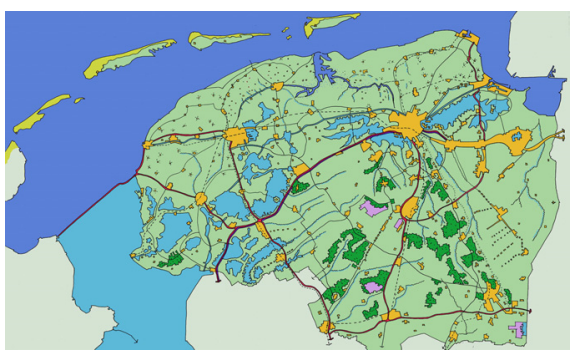

Not directly visible in the right map of Figure 8 is the usage related to the new order of the landscape. It will be obvious that by flooding certain parts, introducing salty water, coupling urban settlements or detaching them for a certain degree of autonomy may seem threats to the present situation, especially when they relate to specific people, their homes and incomes. However, the analysis resulting from the climate change and energy depletion urge, offer various opportunities for new lifestyles (dynamic living, living on water, selfsufficiency) and economies (energy production, trade and knowledge, active and natural tourism, e-commerce, senior living).

\subsection{Visiting cards}

In order to better illustrate the consequences of the new regional map on a lower scale, so-called visiting cards were drawn for specific areas in the region. These are maps meant to inspire, tempt and invite. Figure 9 illustrates two of them. The Eemshaven-Delfzijl area (left), which may be energetically based on a multi-fuel plant (powered by domestic waste, biomass, residual fossil fuel), heat cascades, geothermal heat, an osmosis plant, and solar and wind power. This is perhaps the area richest in energy potentials, and therefore suitable for various developments in the near future. The Emmen area (right) is a much more poor area in energy terms. It forms a link to the peat colonies to the East and higher sand plateau to the West. The peat remaining, industrial and greenhouse developments may be the basis for spatial planning here.

\section{Conclusion}

The approach discussed in this paper implies a new mind-set on spatial planning based on sustainable development and effective use of local energy potentials. 
By clearly translating local features and opportunities into maps, it enables visualisation of sustainable ambitions for the future and the consequence of it to planning. Thereby it proved to be an ideal catalyst for discussions, as opposed to written policy plans. The new approach can be used anywhere in the world, most probably leading to different solutions. A sustainable future has different faces.
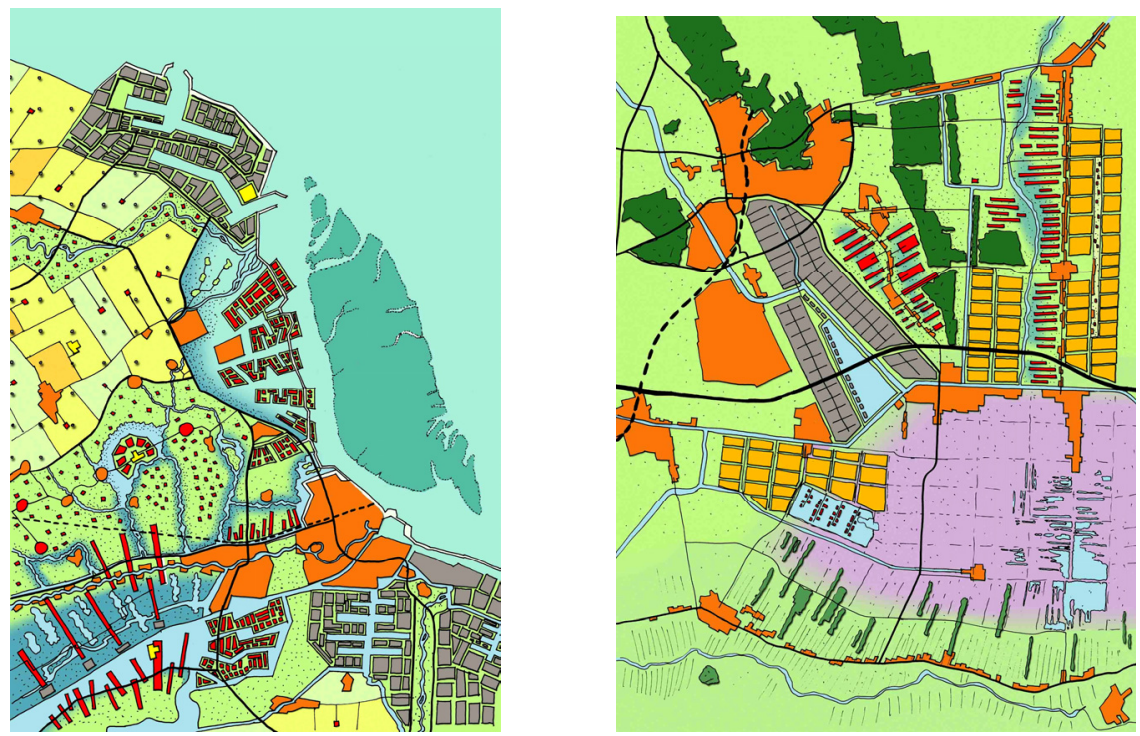

Figure 9: Visiting card for the Eemshaven-Delfzijl area (left) and the Emmen area (right).

\section{References}

[1] IPCC; Climate Change 2001: Synthesis Report (Technical Summary); IPCC: www.ipcc.ch, 2001.

[2] Jong T.M. de (ed.), Moens M.J., Akker C. van den \& Steenbergen C.M.; Sun Wind Water, Earth Life and Living - Legends for design; Delft University of Technology, 2004.

[3] Roggema R., Dobbelsteen A. van den \& Stegenga K. (eds.); Pallet of Possibilities; Groningen, 2006.

[4] Noorman K.J. (ed.) et al.; €nergie(k) Noord-Nederland (in Dutch); Groningen, 2006. 